\title{
Availability and Utilization of Psychosocial Services for Breast Cancer Patients in Addis Ababa, Ethiopia: A Mixed Method Study
}

\author{
Abigiya Wondimagegnehu ( $\sim$ abitowon@gmail.com ) \\ Addis Ababa University School of Public Health https://orcid.org/0000-0002-1491-0959 \\ Workeabeba Abebe \\ Addis Ababa University School of Medicine
}

\section{Selamawit Hirpa Abu}

Addis Ababa University School of Public Health

Eva J. Kantelhardt

Martin Luther University Halle Wittenberg: Martin-Luther-Universitat Halle-Wittenberg

\section{Adamu Addissie}

Addis Ababa University School of Public Health

\section{Bradley Zebrack}

U-M SSW: University of Michigan School of Social Work

\section{Solomon Teferra}

Addis Ababa University School of Medicine

\section{Research Article}

Keywords: psychosocial services, breast cancer, mixed design, Ethiopia

Posted Date: July 21st, 2021

DOI: https://doi.org/10.21203/rs.3.rs-527384/v1

License: (c) (i) This work is licensed under a Creative Commons Attribution 4.0 International License. Read Full License 


\section{Abstract}

Purpose: Although psychosocial services have substantial impact in cancer care, the availability and utilization of these services have not been well-studied in Sub Saharan Africa. Therefore, we explored the types of psychosocial services available for breast cancer patients in Addis Ababa, Ethiopia.

Methods: A mixed method study was conducted using a cross-sectional survey involving 428 breast cancer patients, followed by a qualitative study. A total of nine in-depth interviews (IDIs) were conducted with four breast cancer patients and five key informants using two separate interview guides. In addition to descriptive statistics, logistic regression was done to identify factors associated with provision of psychosocial services. Thematic analysis was used for the qualitative data using NVivo 12 plus software.

Results: Only 47 (11.1\%) patients received psychosocial services, either in the form of counseling, emotional support or provision of information. Health professionals reportedly provided such services along with their routine activities, and patients predominantly received social/emotional support from family members, friends and colleagues. There were no well-structured counseling service, emotional support or group discussion sessions for breast cancer patients in these health facilities. The main reasons for not providing these services were high patient flow/workload, inadequate space, lack of training and not having qualified professionals to organize and deliver psychosocial services in those hospitals.

Conclusions: only one in ten breast cancer patients received psychosocial services from health professionals, and the services were not delivered in a structured way. Therefore, psychosocial services should be integrated both in private and government health facilities of Ethiopia.

\section{Background}

Cancer is a devastating disease causing significant psychological problems among patients and their caregivers [1]. Several studies revealed that cancer patients face emotional, social and psychological difficulties, either in the form of anxiety or depressive disorders [2-5]. Piece of evidence have also suggested that psychological disorders are significantly associated with substantial functional impairment, fatigue, pain, poor quality of life [6, 7] and reduced survival [8]. Particularly, patients with breast cancer who are in the midst of treatment have fear and concerns regarding mortality, disease recurrence, and body image impairment, especially in relation with mastectomy, hormonal treatment, and sexuality $[1,9,10]$.

Psychosocial services are one of the components of cancer care addressing the social, psychological, emotional, spiritual, and functional aspects of the patient's journey with an interdisciplinary team of care and service providers [11]. It includes a variety of psychological and educational components, such as relaxation training, cognitive and behavioral coping strategies, cancer education/information sessions, and group social support [12-14]. Provision of psychosocial services revealed significant effects in the treatment of cancer patients in reducing emotional distress, anxiety, and depression and it also improves adherence to treatment, enhance quality of life and improve survival of cancer patients [15, 18-20].

The significant advances in the effectiveness of psychosocial interventions have encouraged different health organizations, associations, and committees to develop, implement, and disseminate psychosocial guidelines and evidence-based treatments for several co-morbid psychiatric disorders in cancer and other chronic illnesses [21-25]. For instance, the primary vision of the International Psycho-Oncology Society (IPOS) in collaboration with World Health Organization (WHO) is improving the quality of cancer care and cancer policies through provision of psychosocial care globally [26]. Due to its positive impacts on several treatment outcomes, psychosocial services are integrated and being delivered in routine cancer care in high-income countries [10,21, 22, 27]. 
Nevertheless, cancer care systems in many low- and middle-income countries (LMICs) do not even address the current burden of cancer due to poor screening services and poor development of public health services. In addition, ignorance, unhealthy cultural and spiritual beliefs, and denial of diagnosis are common problems that create many challenges in terms of fewer treatment options, presentation at advanced stages of disease and pain management, resulting in a greater need for psychosocial and palliative care. However, psychosocial services are not widely available in LMICs, especially in Africa $[24,28]$. One of the major challenges for not implementing existing clinical practice guidelines for psychosocial care is most of these guidelines have been designed primarily for well-resourced settings, considering their culture and local context $[29,30]$.

So far, few studies have been conducted on the implementation of psychosocial services in LMICS. A qualitative study done in Indonesia reported that breast cancer patients obtained information about their diagnosis and treatment from the doctors in the hospital. However, other types of psychosocial services, such as counseling and emotional support, were not provided for the patients [31]. According to a study done in Botswana, the majority of cancer patients received social support from family members and friends. However, the study revealed that there is a gap in the provision of psychosocial service due to understaffed facilities and both poor referral communications and scheduling systems [32]. Similarly, our previous study in Ethiopia revealed that breast cancer patients received social support from family members, friends and significant others [33]. However, the provision of psychosocial services for breast cancer patients at the health facility level has never been explored before. Therefore, this study will explore the availability and receipt of psychosocial services for breast cancer patients in selected hospitals of Addis Ababa, Ethiopia.

\section{Methods}

\section{Study design and Place}

A sequential mixed study design [QUAN (qual)] was employed; in the first phase of the study, a cross-sectional study design was used and quantitative data was collected from 428 breast cancer patients at two large tertiary referral hospitals and five private oncology clinics. Subsequently, a small-scale qualitative approach was used for further exploration and validation of the quantitative findings. Ethical clearance was obtained from the Research Ethics Committee (REC) of the School of Public Health and Institutional Review Board (IRB) of the College of Health Sciences, Addis Ababa University.

\section{Study participants and sample size}

The sample size for the quantitative part of the study was calculated using these assumptions: $95 \%$ confidence interval $(\mathrm{Cl})$, margin of error $(\mathrm{d})=5 \%, 40.3 \%$ prevalence of depression [34] and $20 \%$ non-response rate. The final calculated sample size was 444 . The eligibility criteria were all pathologically confirmed breast cancer patients above 18 years of age and who were undergoing treatment in those selected health facilities.

In the qualitative part of the study, IDIs were conducted with four purposively selected breast cancer patients and five health professionals (two oncologists, two BSc nurses and one health officer) who were working in the respective oncology departments. An attempt was made to achieve the principle of maximum variation of participants by considering type of health facility, duration of diagnosis, age and place of residence.

\section{Data collection and tools}

For the quantitative part of the study, a structured questionnaire was developed and adapted to our context after reviewing literature; sociodemographic information was included. Breast cancer patients were considered as receiving psychosocial services if they reported having received any kind of counseling service, emotional support or information/educational materials by health professionals working in the current health facility. 
For the qualitative study, two separate interview guides were prepared for IDIs with patients and key informants. The principal investigator and a research assistant who has experience in qualitative research conducted all the interviews. Daily debriefings were held on emerging thematic areas, and the data collection continued until the theoretical saturation level was reached. All the interviews were audio recorded, and notes were taken during the interviews. The data was organized and appropriately labeled immediately after each interview. Subsequently, all recorded interviews were transcribed and translated verbatim.

\section{Data analysis procedures}

The quantitative data was organized in Epi data software and analyzed using Statistical Package for Social Sciences (SPSS) version 25. Bivariate logistic regression analysis was done for each independent variable with receipt of psychosocial services. The crude and adjusted odds ratios (COR and AOR) with 95\% $\mathrm{Cl}$ were presented. The data analysis for the qualitative study was initiated in the field simultaneously with the data collection process. All transcribed documents, field notes and reflexive memos were entered into NVivo12 plus software. Each statement and word were coded line by line based on the stated objectives.

Thematic analysis was used to categorize and explain the emerging thematic areas under each objective. The findings were guided and described using the tiered intervention model, which provides a framework to review existing services within the community, identify gaps in current service delivery, and for implementing psychosocial care using a communitybased approach [35].

\section{Result}

The result of this study is organized and presented in three parts. The first section describes findings from the qualitative study highlighting the types and location of psychosocial services available for breast cancer patients.

The second section deals with the findings from the quantitative survey describing with the proportion of women who received psychosocial services in those health facilities. The analytic result of the survey was conducted among 428 patients, with a response rate of $96.4 \%$. The third section narrates the reasons for not providing psychosocial services for breast cancer patients in those facilities.

Table 1: Characteristics of participants involved in the qualitative study. 


\begin{tabular}{|c|c|c|c|c|c|c|c|c|}
\hline Code & Age & $\begin{array}{l}\text { Place of } \\
\text { residence }\end{array}$ & $\begin{array}{l}\text { Time } \\
\text { since } \\
\text { diagnosis }\end{array}$ & $\begin{array}{l}\text { Educational } \\
\text { status }\end{array}$ & Occupation & $\begin{array}{l}\text { Type of } \\
\text { treatment } \\
\text { received } \\
\text { before }\end{array}$ & $\begin{array}{l}\text { Current } \\
\text { treatment }\end{array}$ & $\begin{array}{l}\text { Type of } \\
\text { hospital }\end{array}$ \\
\hline \multirow[t]{3}{*}{ P01 } & 36 & $\begin{array}{l}\text { Addis } \\
\text { Ababa }\end{array}$ & $\begin{array}{l}\text { Four } \\
\text { years ago }\end{array}$ & $\begin{array}{l}\text { First } \\
\text { degree }\end{array}$ & Bank teller & $\begin{array}{l}\text { Surgery } \\
\text { (mastectomy, } \\
1 \text { breast) } \\
\text { Chemotherapy }\end{array}$ & $\begin{array}{l}\text { Second } \\
\text { round } \\
\text { chemo } \\
\text { (6 } 6^{\text {th }} \\
\text { cycle) }\end{array}$ & Private \\
\hline & & & & & & $\begin{array}{l}\text { Hormonal } 3 \\
\text { yrs } 4 \text { months }\end{array}$ & & \\
\hline & & & & & & Radiotherapy & & \\
\hline \multirow[t]{2}{*}{ P02 } & 42 & $\begin{array}{l}\text { Debre } \\
\text { Markos }\end{array}$ & $\begin{array}{l}\text { Two years } \\
\text { ago }\end{array}$ & Unknown & House wife & $\begin{array}{l}\text { Surgery } \\
\text { (partial } \\
\text { excision) } \\
\text { Chemotherapy }\end{array}$ & $\begin{array}{l}\text { Second } \\
\text { round } \\
\text { chemo } \\
\left(8^{\text {th }}\right. \\
\text { cycle })\end{array}$ & Government \\
\hline & & & & & & $\begin{array}{l}\text { Hormonal } \\
\text { therapy }(>1 \mathrm{yr})\end{array}$ & & \\
\hline P03 & 51 & $\begin{array}{l}\text { Addis } \\
\text { Ababa }\end{array}$ & $\begin{array}{l}\text { Six } \\
\text { months } \\
\text { ago }\end{array}$ & Unknown & Merchant & $\begin{array}{l}\text { Surgery } \\
\text { (Mastectomy } \\
\text { both breasts) }\end{array}$ & $\begin{array}{l}\text { First } \\
\text { cycle } \\
\text { chemo } \\
\left(2^{\text {nd }}\right. \\
\text { cycle })\end{array}$ & Private \\
\hline P04 & 35 & $\begin{array}{l}\text { Dire } \\
\text { Dawa }\end{array}$ & $\begin{array}{l}\text { One year } \\
\text { ago }\end{array}$ & $\begin{array}{l}\text { First } \\
\text { degree }\end{array}$ & $\begin{array}{l}\text { Bank } \\
\text { branch } \\
\text { manager }\end{array}$ & $\begin{array}{l}\text { Surgery } \\
\text { (Mastectomy } 1 \\
\text { breast) }\end{array}$ & $\begin{array}{l}\text { First } \\
\text { cycle } \\
\text { chemo } \\
\text { (4h } \\
\text { cycle) }\end{array}$ & Government \\
\hline
\end{tabular}

\section{Section one: Qualitative study findings}

\section{Theme 1: Available psychosocial services}

The psychosocial services available for breast cancer patients were described and categorized in to two main sub thematic areas: i) from the community and ii) from the health facilities.

\section{Subtheme 1.1: From the community}

Despite the fact that there is an awareness gap and the way the community provides social support has its own limitations, most of breast cancer patients who participated in this study testified that they received various types of emotional support from different groups of people in the community.

\section{a) From family members}

"The good thing, I receive a lot of support from my family. My husband is very supportive, my sisters, my mother and friends. All are very supportive." (P01: 36 years)

\section{b) From close friends}

"My close friends know about it and we always discuss about everything. They comfort me a lot...they are very supportive." (P04: 35 years) 
"Even at work, people usually support me. For example, they reduce workload and give me permission when I have an appointment." (P01: 36 years)

\section{Subtheme 1.2: From health professionals at the health facilities}

\section{a) Disclosure and counseling services}

In those visited health facilities, there was no structured way of disclosing breast cancer patients. But most of the time, the physician who made the diagnosis was the one who disclosed the diagnosis to patients; this was also reported by patients.

"There was a doctor who did the diagnosis and disclosed me as I have cancer." (P04: 35 years)

"The doctor is the one who handles most of these issues using the short time he has for examining all the patients. He provides the counseling service based on patient's knowledge and condition." (HP04: Health officer, private)

On the other hand, there were breast cancer patients who accidentally got disclosed during the waiting time or when they were linked to an oncologist. Sometimes cancer patients remained undisclosed about their status. Respondents mentioned caregivers who informed the health professionals not to tell the patient about cancer because of fear of discontinuing the treatment and in order to prevent hopelessness.

"They didn't tell me anything about the disease except telling me that I will be linked to another doctor ... Then, I heard from other patient beside me that we are waiting for a cancer doctor." (P01: 36 years)

"Sometimes, patients bring their pathology result without being informed about their diagnosis...the family members insist us not to tell them and the doctor will not say anything." (HP03: BSc nurse, private)

All breast cancer patients who participated in the qualitative study reported that they did not receive any counseling services. They even mentioned that they were not properly disclosed and the health professionals didn't provide any emotional support or counseling at the time of diagnosis.

"The way he disclosed me was really shocking. Then, I isolated myself from any kind of medical treatment. The doctor told me as its breast cancer, and as there is no option other than removing my breast. I even asked him about the cause and he said we don't have time to discuss about this; rather we have to focus on the solution. That's all what he said to me." (P04:

\section{5 years)}

In contrast, the health professionals reported that they were providing counseling services and emotional support for cancer patients as much as the situation allowed them. However, except having short and brief discussions with each patient, there were no structured psychosocial services, which included counseling, emotional support and discussion sessions with cancer patients either individually or as a group. The physicians and nurses who were working in the oncology unit provided these services along with their other routine tasks.

"We do not have such structured system, even the psychological support and counseling is not provided adequately. But we are trying our best and we need both counselors and clinical psychologists." (HP01, Oncologist)

Table 2: Characteristics of key informants participated in the qualitative study 


\begin{tabular}{|c|c|c|c|c|}
\hline Code & Profession & Year of experience & Year of experience at the oncology department & Type of the hospital \\
\hline HP01 & Oncologist & 27 years & 10 years & Government \\
\hline HP02 & Oncologist & 15 years & 11 years & Government \\
\hline HP03 & $\begin{array}{l}\text { Clinical } \\
\text { nurse }\end{array}$ & 10 years & 8 years & Private \\
\hline HP04 & $\begin{array}{l}\text { Clinical } \\
\text { nurse }\end{array}$ & 5 years & 4 years & Government \\
\hline HP05 & Health officer & 2 years & 2 years & Private \\
\hline
\end{tabular}

\section{b) Provision of adequate information and brochures}

Few participants reported that they received some information from health professionals about the treatment options, side effects and duration of treatment.

"When I start chemotherapy, the doctor told me that the treatment has an effect on my hair and as I should not be worried about it." (PO2: 42 years)

However, most of the patients indicated that the information provided by health professionals was not adequate and the majority of breast cancer patients discussed among themselves and got a lot of information from other patients who were diagnosed earlier.

"No, I was not even informed about the no of cycles prescribed for me. On the third cycle, I asked the nurse and told me as its six cycles." (P04: 35 years)

"We usually talk among ourselves and get a lot of information from those patients who took the medication earlier." (P02:

\section{5 years)}

Concerning the provision of leaflets and brochures, none of the participants mentioned that they received such kind of educational materials. The health professionals also reported that they did not usually give those materials to their patients.

"No, noone gave me such kind of materials." (P01: 36 years)

"We try our best to help the patients with what we can but we do not provide educational materials or other supports."

(HP01: Oncologist)

\section{Section two: Quantitative study findings}

Concerning psychosocial services received, our quantitative study revealed that only $47(11.0 \%)$ of these patients have received any kind of psychosocial service in the current health facility, either in the form of counseling, emotional support or provision of information from health professionals. Out of these patients, more than half 27 (57.6\%) received information from the health professionals, while the others received other forms of psychosocial services. Most 356 (83.2\%) of the breast cancer patients stated that they preferred to visit health facilities in order to receive psychosocial services, 70 (16.4\%) of them preferred religious places and only $2(0.5 \%)$ preferred traditional healers or other people.

Even though, majority of participants are still involving in different social activities, $75(17.5 \%)$ of the total participants reported that the disease affected different aspects of their life. Out of these, $46(61.3 \%)$ and $32(42.6 \%)$ of the patients stated that the disease affected their social and spiritual life respectively (Table 3 ). 
Table 3: Type of psychosocial service received in selected health facilities in Addis Ababa, Ethiopia 
Variables

Patients reaction at the time of diagnosis $(n=354)$ $\mathrm{n}$

Percent (\%)

$\begin{array}{lcc}\text { I was shocked \& cried } & 207 & 58.5 \\ \text { Deep sadness } & 60 & 16.9 \\ \text { Hopelessness and fear of death } & 14 & 4.0 \\ \text { I didn't feel anything } & 50 & 14.1 \\ \text { Others* } & 23 & 6.5\end{array}$

Know about their disease status

$\begin{array}{lll}\text { Breast cancer } & 354 & 82.7 \\ \text { Breast Tumor and inflammation } & 61 & 14.3 \\ \text { Don't know } & & \end{array}$

$13 \quad 3.0$

Ever received counseling service

No

$371 \quad 86.7$

Yes

$57 \quad 13.3$

Currently receiving any psychosocial service in this facility

No

$381 \quad 89.0$

Yes

$47 \quad 11.0$

Type of psychosocial service received

$(n=47)$

$\begin{array}{lll}\text { Counseling service } & 9 & 19.1 \\ \text { Emotional support } & 11 & 23.4 \\ \text { Provision of information } & 27 & 57.4\end{array}$

Participate in different gatherings

$\begin{array}{lll}\text { No } & 28 & 6.5 \\ \text { Yes } & 400 & 93.5\end{array}$

Type of gatherings

( $n=428$ for each type)

Spiritual

32876.6

Only Funeral

$323 \quad 75.5$

Social

$240 \quad 56.1$

Women

$125 \quad 29.2$

Political

$32 \quad 7.5$

Challenges in relation to the disease 
Type of challenges encountered

( $n=75$ for each type)

\begin{tabular}{lll} 
Problem on social activities & 46 & 61.3 \\
Problem on spiritual life & 32 & 42.6 \\
\hline Problem with family & 27 & 36.0 \\
Problem with employer & 22 & 29.3
\end{tabular}

Preferred place to receive psychosocial support

$\begin{array}{llc}\text { Health facilities } & 356 & 83.2 \\ \text { Religious places } & 70 & 16.4 \\ \text { Traditional healers' other people } & 2 & 0.5\end{array}$

According to the multivariate analysis, residence was one of the sociodemographic factors that was significantly associated with receipt for psychosocial care. The odds of breast cancer patients who live in Addis Ababa were 2.54 times more likely to receive any psychosocial services as compared to those who came from outside of Addis Ababa [AOR $=2.54$ $(95 \% \mathrm{Cl} 1.30,6.27)]$. Clinical factors such as severity of pain and date of diagnosis, also had a significant association with receiving psychosocial services. Breast cancer patients who had moderate pain were three times more likely to receive psychosocial services as compared to those women without any pain. [AOR $=2.84(95 \% \mathrm{Cl} 1.02,7.94)$. The odds of women who were diagnosed more than 1 year ago were three times more likely to receive the service as compared to those who were recently diagnosed $(<1$ year) $[\mathrm{AOR}=3.17(95 \% \mathrm{Cl} 1.27,7.89)]$ (Table 4).

Table 4: Multivariate logistic regression model for factors for receiving psychosocial service among Breast Cancer Patients in Addis Ababa, Ethiopia

\section{Section three: Qualitative study findings}

\section{Theme 2: Determinants of psychosocial services provision}

Reasons for not providing psychosocial services in these health facilities were also explored in the qualitative part of the study, and several justifications were given by the key informants. These included shortage of staff, high workload and not having an assigned person who will deliver these services in an organized way.

"The main problem is staff shortage and high patient flow...umm.... we do not have a staff who is assigned for psychosocial activities..." (HP04: BSc nurse, government)

In addition to this, there was high patient flow in these health facilities due to the limited number of cancer centers in the country. Therefore, it was difficult for the health professionals to spend more time with each patient and address their emotional and psychosocial needs.

"I don't know the reason, but I think it's because of high patient flow. Let alone to spend some time with you and discuss about your disease condition, the medication by itself is given in hurry." (P02: 42 years; BC patient)

"...because of the high patient flow, doctors are forced to see many patients per day specially in government hospitals." (HP02: Oncologist) 


\begin{tabular}{|c|c|c|c|c|}
\hline Variables & & Crude OR $(95 \% \mathrm{Cl})$ & Adjusted OR (95\% Cl) & The other \\
\hline \multirow[t]{2}{*}{ Health facilities } & Government & 1 & 1 & \multirow{3}{*}{$\begin{array}{l}\text { lack of skill / } \\
\text { training on how } \\
\text { to provide } \\
\text { counseling and } \\
\text { ther }\end{array}$} \\
\hline & Private & $1.57(0.58,4.13)$ & $1.67(0.46,6.03)$ & \\
\hline Age & & $1.04(1.01,1.08)^{*}$ & $1.04(0.99,1.08)$ & \\
\hline \multirow[t]{2}{*}{ Residence } & Outside Addis & 1 & 1 & \multirow{6}{*}{$\begin{array}{l}\text { professional } \\
\text { supports. They } \\
\text { also stated that } \\
\text { the setup by } \\
\text { itself was not } \\
\text { convenient to } \\
\text { provide } \\
\text { individual } \\
\text { counseling for } \\
\text { the patients. }\end{array}$} \\
\hline & Inside Addis & $1.87(0.97,3.52)$ & $2.54(1.30,6.27)^{*}$ & \\
\hline \multirow[t]{5}{*}{ Marital status } & Single & 1 & 1 & \\
\hline & Married & $2.00(0.87,4.62)$ & $2.35(0.91,6.08)$ & \\
\hline & Cohabitated & $0.87(0.23,3.24)$ & $1.53(0.25,9.52)$ & \\
\hline & Divorced & $2.70(0.76,9.30)$ & $2.61(0.63,10.91)$ & \\
\hline & Widowed & $3.01(0.92,9.56)$ & $2.05(0.49,8.62)$ & $\begin{array}{l}\text { "There are no } \\
\text { trained } \\
\text { personnel which }\end{array}$ \\
\hline \multirow[t]{5}{*}{ Severity of pain } & & & & \multirow{5}{*}{$\begin{array}{l}\text { makes it difficult } \\
\text { to provide } \\
\text { counseling } \\
\text { service." (HP05: } \\
\text { Health officer, } \\
\text { private) }\end{array}$} \\
\hline & None (0) & 1 & 1 & \\
\hline & Mild (1-3) & $2.09(1.02,4.28)^{*}$ & $1.93(0.82,4.53)$ & \\
\hline & Moderate (4-6) & $3.21(1.29,7.99) *$ & $2.84(1.02,7.94)^{*}$ & \\
\hline & Severe $(7-10)$ & $2.78(0.59,13.12)$ & $2.44(0.46,12.92)$ & \\
\hline \multirow{5}{*}{ Final stage of cancer } & & & & \multirow{8}{*}{$\begin{array}{l}\text { "The patients are } \\
\text { very eager to } \\
\text { listen. But the } \\
\text { issue is we do } \\
\text { not have } \\
\text { adequate room } \\
\text { for counseling } \\
\text { services" (HP04: } \\
\text { BSc nurse, } \\
\text { government) }\end{array}$} \\
\hline & Stage I & 1 & 1 & \\
\hline & Stage II & $0.62(0.13,2.81)$ & $0.88(0.17,4.49)$ & \\
\hline & Stage III & $0.42(0.09,1.89)$ & $0.65(0.13,3.29)$ & \\
\hline & Stage IV & $1.20(0.16,9.04)$ & $1.18(0.14,10.17)$ & \\
\hline \multirow[t]{3}{*}{ Chemotherapy } & & & & \\
\hline & No & 1 & 1 & \\
\hline & Yes & $0.53(0.18,1.52)$ & $0.34(0.076,1.57)$ & \\
\hline \multirow[t]{3}{*}{ Duration of Dx } & & & & Discussion \\
\hline & Less than $1 \mathrm{yr}$ & 1 & 1 & \multirow{2}{*}{$\begin{array}{l}\text { In this study, } \\
\text { majority of } \\
\text { breast cancer }\end{array}$} \\
\hline & More than $1 \mathrm{yr}$ & $2.95(1.26,6.86)^{*}$ & $3.17(1.27,7.89)^{*}$ & \\
\hline
\end{tabular}

social support from their family members, friends and colleagues. This finding is consistent with other studies conducted in China [36], Turkey [37] and Botswana [32], which reported that cancer patients often received psychosocial supports from their family members and friends. 
Regarding disclosure of cancer diagnosis, several guidelines recommended that all cancer patients should be well-informed about their diagnosis, treatment options and future prognosis of the disease [23-25,38]. However, our study found that there were some breast cancer patients who were not even aware of their diagnosis. A previous study conducted in Ethiopia also reported a similar finding concerning lack of disclosure of cancer diagnosis among breast and cervical cancer patients [39]. This finding is not only in Ethiopia but also supported by a quantitative study conducted in Egypt that revealed around $15 \%$ of cancer patients were not aware of their diagnosis, and only their family members were aware of their diagnosis [40]. The main reason assumed by interviewees for not disclosing to these patients was the pressure of relatives on caregivers to prevent hopelessness and discontinuation of treatment. This reason is also consistent with a study done in India, which reported that the majority of caregivers preferred non-disclosure of cancer diagnosis and prognosis to their patients [41]. Poor disclosure of cancer diagnosis in developing countries might be associated with poor educational attainment [40], preference of traditional medicine, old age and having other chronic illnesses [42].

In this study, majority of breast cancer patients reported that they didn't receive counseling services in their current health facility. However, counseling services were one of the major components of psychosocial services that are being delivered in developed countries [11, 23-26, 43,44]. According to the cancer survivorship plan of the Institute of Medicine (IOM), a minimum of care and information that should be given for each cancer patient includes provision of information about the type of tests, results, tumor characterization, and treatment details, including type, combination of treatment, duration, side effects and regimen [10]. Nevertheless, patients in this study mentioned that they didn't get all the necessary details about their diagnosis and treatment, including the number of chemotherapy cycles prescribed for them. They also stated that they never received educational materials, either brochure or leaflets. Similarly, many African countries do not provide such comprehensive psychosocial services, including counseling and provision of information materials for cancer patients [26, $28,45]$. The possible explanation for this variation in the provision of psychosocial services between developed and developing countries is lack of resources, whether it be skilled man power, infrastructure, materials and so on. Furthermore, this might also be associated with the perception of health professionals towards the capacity of mostly illiterate patients to comprehend and appropriately interpret all these details.

Those patients who are residents of Addis Ababa were two times more likely to receive psychosocial services compared to others who were residing outside of Addis Ababa. This finding can be explained by the fact that people living in urban areas probably have better health information and therefore insist on obtaining psychosocial services. This finding is supported by a study conducted in Egypt, which revealed that educational level and place of residence were significantly associated factors with regard to disclosure and provision of psychosocial services [40].

A main strength of the quantitative study is the large sample size and inclusion of private and government hospitals in Addis Ababa, leading to a broad picture of the situation. Maximum variation of responses was achieved through including newly diagnosed and recurrent cases. During our qualitative study, collecting information from patients and also health professionals increased the generalizability of the study. The major limitation of this study was that we only conducted IDIs, and it might be helpful if other data collection techniques, such as focus group discussion (FGD) were used in order to triangulate our findings.

\section{Conclusions}

In this study, psychosocial services were barely found for breast cancer patients, either in the form of counseling services, emotional support or provision of information. Except provision of irregular type of emotional support and counseling services for the patients, there was no structured and well-organized psychosocial services in those health facilities. High patient flow, workload, inadequate space and lack of trained health professionals were the major reasons for not providing psychosocial services. The key informants mentioned that psychosocial services are one of the neglected areas in cancer care, which requires due attention. It's recommended that psychosocial services should be integrated in routine cancer care, at least at secondary and tertiary hospitals in the country. It's also indicated that the service should be tailored in the local

Page $12 / 16$ 
context through considering various sociocultural factors, educational attainment of the community and available resources in the country. Further studies are required to identify other barriers in provision of this service and in order to explore the psychosocial challenges and needs among all cancer patients in different parts of the country.

\section{Abbreviations}

AOR, Adjusted Odds Ratio; IOM, Institute of Medicine; IPOS, International Psycho-Oncology Society; IRB, Institutional Review Board; LMICs, Low- and Middle-Income Countries; PFSA, Food and Safety Authority; REC, Research Ethics Committee; WHO, World Health Organization.

\section{Declarations}

Ethics approval and consent to participate: Ethical clearance of this study was obtained from the Research Ethics Committee of the School of Public Health and Institutional Review Board of the College of Health Science, Addis Ababa University. Written informed consent was obtained from all participants. The confidentiality and anonymity of the participants was maintained. All analysis methods were performed in accordance with the Declaration of Helsinki.

Consent for publication: Not applicable.

Availability of data and material: The datasets used and/or analyzed during the current study are available from the corresponding author on reasonable request.

Competing interests: The authors declare that they have no competing interests.

Funding: This study is supported by the Department of Psychiatry, College of Health Sciences, AAU. The funding body didn 't get involved in the design of the study and collection, analysis and interpretation of data and in writing the manuscript.

\section{Authors' contributions}

All authors conceived and designed the study. AW and SH conducted the IDIs. AW, SH, WA and AA performed the data analysis and interpretation of the findings. AW and WA drafted the manuscript. BZ, EK, AA and ST were actively involved in data interpretation and critically reviewed the manuscript. All authors read and approved the final manuscript.

\section{Acknowledgement}

The authors would like to thank Dr. Aynalem Abraha form department of oncology and the Women's Health Research Working Group (WHRWG) especially Dr. Mitike Molla for their additional ideas and suggestions at the inception of the study. They also would like to thank the seven health facilities and those breast cancer patients and key informants who were willing to participate in the study.

\section{References}

1. Grassi L, Spiegel D, Riba M. Advancing psychosocial care in cancer patients. F1000Res. 2017; 6:2083.

2. Vin-Raviv N, Akinyemiju TF, Galea S, Bovbjerg DH. Depression and anxiety disorders among hospitalized women with breast cancer. PLoS One. 2015; 10:e0129169.

3. Alacacioglu A, Ulger E, Varol U, Yildiz I, Salman T, Bayoglu V, et al. Depression, anxiety and sexual satisfaction in breast cancer patients and their partners-Izmir Oncology Group Study. Asian Pac J Cancer Prev. 2014; 15:10631-6.

4. Nikbakhsh N, Moudi S, Abbasian S, Khafri S. Prevalence of depression and anxiety among cancer patients. Caspian J Intern Med 2014; 5:167-70.

Page $13 / 16$ 
5. Zainal NS, Nik-Jaafar NR, Baharudin A, Sabki ZA, Ng CG. Prevalence of depression in breast cancer survivors: a systematic review of observational studies. Asian Pac J Cancer Prev. 2013; 14:2649-56.

6. Ardebil MD, Bouzari Z, Shenas MH, Masoud Keighobadi. Depression and health related quality of life in breast cancer patients. [Retracted in: J Pak Med Assoc. 2016; 66:496]. J Pak Med Assoc. 2013; 63:69-71.

7. Reyes-Gibby CC, Anderson KO, Morrow PK, Shete S, Hassan S. Depressive symptoms and health-related quality of life in breast cancer survivors. Journal Womens Health (Larchmt). 2012; 21:311-8.

8. Walker J, Hansen CH, Martin P, Symeonides S, Ramessur R, Murray G, et al. Prevalence, associations, and adequacy of treatment of major depression in patients with cancer: a cross-sectional analysis of routinely collected clinical data. Lancet Psychiatry. 2014; 1:343-50.

9. American Cancer Society. Body image and sexuality after breast cancer. 2019. https://www.cancer.org/cancer/breastcancer/living-as-a-breast-cancer-survivor/body-image-and-sexuality-after-breast-cancer.html. Accessed date: September, 2029.

10. Christ G, Messner C, Behar L, editors. Handbook of oncology social work: psychological care for people with cancer. Oxford: Oxford University Press; 2015.

11. Turnbull Macdonald GC, Baldassarre F, Brown P, Hatton-Bauer J, Li M, Green E, et al. Psychosocial care for cancer: a framework to guide practice, and actionable recommendations for Ontario. Curr Oncol. 2012; 19:209-16.

12. Daniels S. Cognitive behavior therapy for patients with cancer. J Adv Pract Oncol. 2015;6:54-6.

13. Xiao F, Song X, Chen Q, Dai Y, Xu R, Qiu C, et al. Effectiveness of psychological interventions on depression in patients after breast cancer surgery: a meta-analysis of randomized controlled trials. Clin Breast Cancer. 2017; 17:171-9.

14. Reese C, Weis J, Schmucker D, Mittag O. Development of practice guidelines for psychological interventions in the rehabilitation of patients with oncological disease (breast, prostate, or colorectal cancer): methods and results. Psychooncology. 2017; 26:1513-8.

15. Guo Z, Tang HY, Li H, Tan SK, Feng KH, Huang YC, et al. The benefits of psychosocial interventions for cancer patients undergoing radiotherapy. Health Qual Life Outcomes 2013; 11:121.

16. D'Abramo F, Goerling U, Guastadisegni C. Targeted drugs and psycho-oncological intervention for breast cancer patients. J Negat Results Biomed. 2016;15:6.

17. Parahoo K, McDonough S, McCaughan E, Noyes J, Semple C, Halstead EJ, et al. Psychosocial interventions for men with prostate cancer: a Cochrane systematic review. BJU Int. 2015; 116:174-83.

18. Hoon LS, Chi Sally CW, Hong-Gu H. Effect of psychosocial interventions on outcomes of patients with colorectal cancer: a review of the literature. Eur J Oncol Nurs. 2013; 17:883-91.

19. Fu WW, Popovic M, Agarwal A, Milakovic M, Fu TS, McDonald R, et al. The impact of psychosocial intervention on survival in cancer: a meta-analysis. Ann Palliat Med. 2016; 5:93-106.

20. Mirosevic S, Jo B, Kraemer HC, Ershadi M, Neri E, Spiegel D. "Not just another meta-analysis": sources of heterogeneity in psychosocial treatment effect on cancer survival. Cancer Med. 2019; 8:363-73.

21. Andersen BL, Dorfman CS. Evidence-based psychosocial treatment in the community: considerations for dissemination and implementation. Psychooncology. 2016; 25:482-90.

22. Rubin G, Berendsen A, Crawford SM, Dommett R, Earle C, Emery J, et al. The expanding role of primary care in cancer control. Lancet Oncol. 2015; 16:1231-72.

23. Grassi L, Watson M. Psychosocial care in cancer: an overview of psychosocial programmes and national cancer plans of countries within the International Federation of Psycho-Oncology Societies. Psychooncology. 2012; 21:1027-33.

24. National Breast Cancer Centre and National Cancer Control Institute. Clinical practice guidelines for the psychosocial care of adults with cancer. Camperdown, NSW: National Breast Cancer Centre; 2003. 
25. Recklitis CJ, Syrjala KL. Provision of integrated psychosocial services for cancer survivors post-treatment. Lancet Oncol. 2017; 18:e39-50.

26. Travado L, Bultz BD, Ullrich A, Asuzu CC, Turner J, Grassi L, et al. 2016 President's Plenary International PsychoOncology Society: challenges and opportunities for growing and developing psychosocial oncology programmes worldwide. Psychooncology. 2017; 26:1231-8.

27. Fennell KM, Turnbull DA, Bidargaddi N, McWha JL, Davies M, Olver I. The consumer-driven development and acceptability testing of a website designed to connect rural cancer patients and their families, careers and health professionals with appropriate information and psychosocial support. Eur J Cancer Care (Engl). 2017; 26. doi:10.1111/ecc.12533.

28. Grassi L, Fujisawa D, Odyio P, Asuzu C, Ashley L, Bultz B, et al. Disparities in psychosocial cancer care: a report from the International Federation of Psycho-oncology Societies. Psychooncology. 2016; 25:1127-36.

29. Andersen BL, DeRubeis RJ, Berman BS, Gruman J, Champion VL, Massie MJ, et al. Screening, assessment, and care of anxiety and depressive symptoms in adults with cancer: an American Society of Clinical Oncology guideline adaptation. J Clin Oncol. 2014; 32:1605-19.

30. Lechner SC, Ennis-Whitehead N, Robertson BR, Annane DW, Vargas S, Carver CS, et al. Adaptation of a psychooncology intervention for black breast cancer survivors: Project CARE. The Couns Psychol. 2012; 41:286-312.

31. Iskandarsyah A, de Klerk C, Suardi DR, Soemitro MP, Sadarjoen SS, Passchier J. Psychosocial and cultural reasons for delay in seeking help and nonadherence to treatment in Indonesian women with breast cancer: a qualitative study. Health Psychol. 2014; 33:214-21.

32. Brown CA, Kohler RE, John O, Motswetla G, Mmalane M, Tapela N, et al. Multilevel factors affecting time to cancer diagnosis and care quality in Botswana. Oncologist. 2018; 23:1453-60.

33. Wondimagegnehu A, Abebe W, Abraha A, Teferra S. Depression and social support among breast cancer patients in Addis Ababa, Ethiopia. BMC Cancer. 2019; 19:836.

34. Popoola AO, Adewuya AO. Prevalence and correlates of depressive disorders in outpatients with breast cancer in Lagos, Nigeria. Psychooncology. 2012; 21:675-9.

35. Hutchison SD, Steginga SK, Dunn J. The tiered model of psychosocial intervention in cancer: a community based approach. Psychooncology. 2006; 15:541-6.

36. Su JA, Yeh DC, Chang CC, Lin TC, Lai CH, Hu PY, et al. Depression and family support in breast cancer patients. Neuropsychiatr Dis Treat. 2017; 13:2389-96.

37. Bener A, Alsulaiman R, Doodson L, Agathangelou T. Depression, hopelessness and social support among breast cancer patients: in highly endogamous population. Asian Pac J Cancer Prev. 2017; 18:1889-96.

38. Montazeri A, Tavoli A, Mohagheghi MA, Roshan R, Tavoli Z. Disclosure of cancer diagnosis and quality of life in cancer patients: should it be the same everywhere? BMC Cancer. 2009; 9:39.

39. Gebremariam A, Yalew AW, Hirpa S, Wondimagegnehu A, Kaba M, Assefa M, et al. Application of the rapid ethical assessment approach to enhance the ethical conduct of longitudinal population based female cancer research in an urban setting in Ethiopia. BMC Med ethics. 2018; 19:87.

40. Alsirafy SA, Abdel-Kareem SS, Ibrahim NY, Abolkasem MA, Farag DE. Cancer diagnosis disclosure preferences of family caregivers of cancer patients in Egypt. Psychooncology. 2017; 26:1758-62.

41. Nyblade L, Stockton M, Travasso S, Krishnan S. A qualitative exploration of cervical and breast cancer stigma in Karnataka, India. BMC Womens Health. 2017; 17:58.

42. Bruwer Z, Futter M, Ramesar R. Communicating cancer risk within an African context: experiences, disclosure patterns and uptake rates following genetic testing for Lynch syndrome. Patient Educ Couns. 2013; 92:53-60.

43. Surbone A, Baider L, Weitzman TS, Brames MJ, Rittenberg CN, Johnson J. Psychosocial care for patients and their families is integral to supportive care in cancer: MASCC position statement. Support Care Cancer. 2010; 18:255-63.

Page $15 / 16$ 
44. Eichler M, Hechtner M, Wehler B, Buhl R, Stratmann J, Sebastian M, et al. Use of psychosocial services by lung cancer survivors in Germany: results of a German multicenter study (LARIS). Strahlenther Onkol. 2019; 195:1018-27.

45. Ashley L, Lawrie I. Tackling inequalities in cancer care and outcomes: psychosocial mechanisms and targets for change. Psychooncology. 2016; 25:1122-6. 